\title{
Chemical Interactions Between Cemented Carbide and Difficult- to-Machine Materials by Diffusion Couple Method and Simulations
}

\author{
L. von Fieandt ${ }^{1} \cdot$ R. M'Saoubi ${ }^{2}$ - M. Schwind ${ }^{2}$ B. Kaplan ${ }^{3}$ - C. Århammar ${ }^{4}$ \\ B. Jansson ${ }^{5}$
}

Submitted: 29 October 2017/in revised form: 20 February 2018/Published online: 11 June 2018

(C) The Author(s) 2018

\begin{abstract}
A simple and efficient diffusion couple method is utilized to study the chemical interactions between cemented carbide cutting tools and difficult-to-machine materials (Ti, Ti-6Al-4V, Ni, Inconel 718, Fe, and AISI 316L). The experimental results and simulations probe different chemical interactions between the cemented carbide and work materials. In particular, the formation of a thick TiC layer is observed at the cemented carbide/Ti and Ti-6Al-4V interface while $\eta$-phase is formed at the interface between the cemented carbide and work materials Inconel 718, Fe and AISI 316L. Pure titanium and Ti-6Al$4 \mathrm{~V}$ both interact strongly with the tool causing formation of $\mathrm{TiC}$ and dissolution of WC-grains. Experiments and diffusion simulations confirm bcc-W formation and progressive diffusion of $\mathrm{W}$ into bec-Ti. For both $\mathrm{Ti}$ and $\mathrm{Fe}$ work materials a dense band of carbides $(\mathrm{WC}+\eta$ or $\mathrm{WC}+$ $\mathrm{TiC}$ ) forms at the interface, effectively inhibiting further diffusion. Ni does not form any stable carbide and lowers the $\eta$-phase limit in terms of carbon content, wherefore diffusion can occur freely. The diffusion couple method used in this work, corroborated by DICTRA simulations
\end{abstract}

\section{C. ̊̊rhammar}

cecilia.arhammar@disruptivematerials.com;

cecilia.arhammar@angstrom.uu.se

1 Department of Chemistry-Ångström Laboratory, Uppsala University, Box 538, 75120 Uppsala, Sweden

2 R\&D Material and Technology Development, Seco Tools AB, 73782 Fagersta, Sweden

3 Sandvik Coromant R\&D, Lerkrogsvägen 19, 12680 Stockholm, Sweden

4 Department of Engineering Sciences-Ångström Laboratory, Uppsala University, Box 534, 75121 Uppsala, Sweden

5 Fagersta, Sweden should serve as a useful tool in the detailed analysis of worn tools where chemical wear is dominant.

Keywords cemented carbide · DICTRA modeling · diffusion couples $\cdot$ machining

\section{Introduction}

Titanium and titanium based alloys are increasingly used for aerospace, medical, marine and chemical processing applications. ${ }^{[1]}$ Thus, the need for high productivity when machining those materials grows stronger. Similarly, nickel based alloys are used due to their excellent properties for demanding applications, where high temperature stability and corrosion resistance are important properties. ${ }^{[2]}$ These alloys are classified as difficult to cut materials, mainly due to high cutting temperatures and adhesion of work material on the cutting tool edge. Given the great need of products, and the difficulty to produce them, it is of interest to study interactions between cemented carbide and these materials.

By far, the most common work material used in any cutting operation is steel. Cemented carbide interacts with steels in diverse ways depending on the alloying elements. Since steel finds so many important applications, machining this work material with high productivity is vital.

An increased understanding of the mechanisms responsible for tool degradation and failure can provide means to design better cutting tool materials and achieve more profitable machining. In many preceding studies, it is stated that the dominating wear mechanism at high temperature is chemical wear. ${ }^{[3]}$ Therefore it is of interest to study high temperature interactions between cutting tools and work materials on a controlled laboratory scale. 
A few different approaches for diffusion couple testing have been used in the past. ${ }^{[4-8]}$ Common for most of these methods is either complex sample preparation or the limitation in studying only one diffusion couple at a time. Recently, Hatt et al. ${ }^{[7]}$ utilized a diffusion couple method similar to the one presented in this work to study the interaction between cemented carbide and titanium alloys. Hatt et al. could thereby explain phase formation due to diffusion and interface reactions. In Hatt's method, the interface is created by pressing the workpiece and tool together. The present authors have developed a relatively simple and flexible diffusion couple method which utilizes the difference in thermal expansion in the work material and the cutting tool to achieve a good contact at the interface between the materials during annealing. In this work, the capability of the suggested diffusion-couple method is demonstrated by a detailed experimental investigation along with diffusion simulations of difficult to machine materials ( $\mathrm{Ti}, \mathrm{Ti}-6 \mathrm{Al}-4 \mathrm{~V}, \mathrm{Ni}$, Inconel 718, Fe and AISI 316L).

\section{Experimental}

\subsection{Sample Preparation}

The sample preparation consisted of inserting a rod of the desired work material into the hole of a cemented carbide insert (Fig. 1a and b), and then slightly deforming the ends of the rod by mechanical compression to ensure good contact (Fig. 1c and d). In this case, the cemented carbide inserts had the geometry ISO SNMA150612 and consisted of WC-Co with 9.6 at.\% (6 wt.\%) Co. In Fig. 1 a typical diffusion couple specimen using the method described in this work is displayed. The different work materials are presented in Table 1.

The samples were annealed in a sintering furnace at $1100{ }^{\circ} \mathrm{C}$ for $2 \mathrm{~h}$ under $\mathrm{Ar}$ atmosphere at $5.5 \mathrm{kPa}$ pressure, with a heating rate of $\sim 5.5^{\circ} \mathrm{C} / \mathrm{min}$ and a subsequent cooling rate of $\sim 10{ }^{\circ} \mathrm{C} / \mathrm{min}$. The higher thermal expansion of the work materials will ensure a well-defined toolwork material interface. After annealing, the samples were ground on the rake face of the insert and subsequently polished using $1 \mu \mathrm{m}$ diamond suspension.

\subsection{Characterization}

The characterisation of the diffusion couple specimens was carried out using a variety of experimental methods.

Light optical microscopy (LOM) was employed using a Zeiss microscope in combination with Murakami's etchant for the samples where $\eta$-phase was suspected $(\mathrm{Fe}, 316 \mathrm{~L}$ and Inconel718). Scanning electron microscopy (SEM) was performed using a LEO ultra 55 FEG-SEM equipped with a Noran-Energy dispersive spectroscopy (EDS) detector. The Inconel 718, nickel and titanium based samples were analyzed using SEM. EDS analysis was employed to analyze the Titanium sample. Wavelength dispersive spectroscopy (WDS) analysis was carried out for the Ni-based sample using a JEOL JXA-8530F instrument.

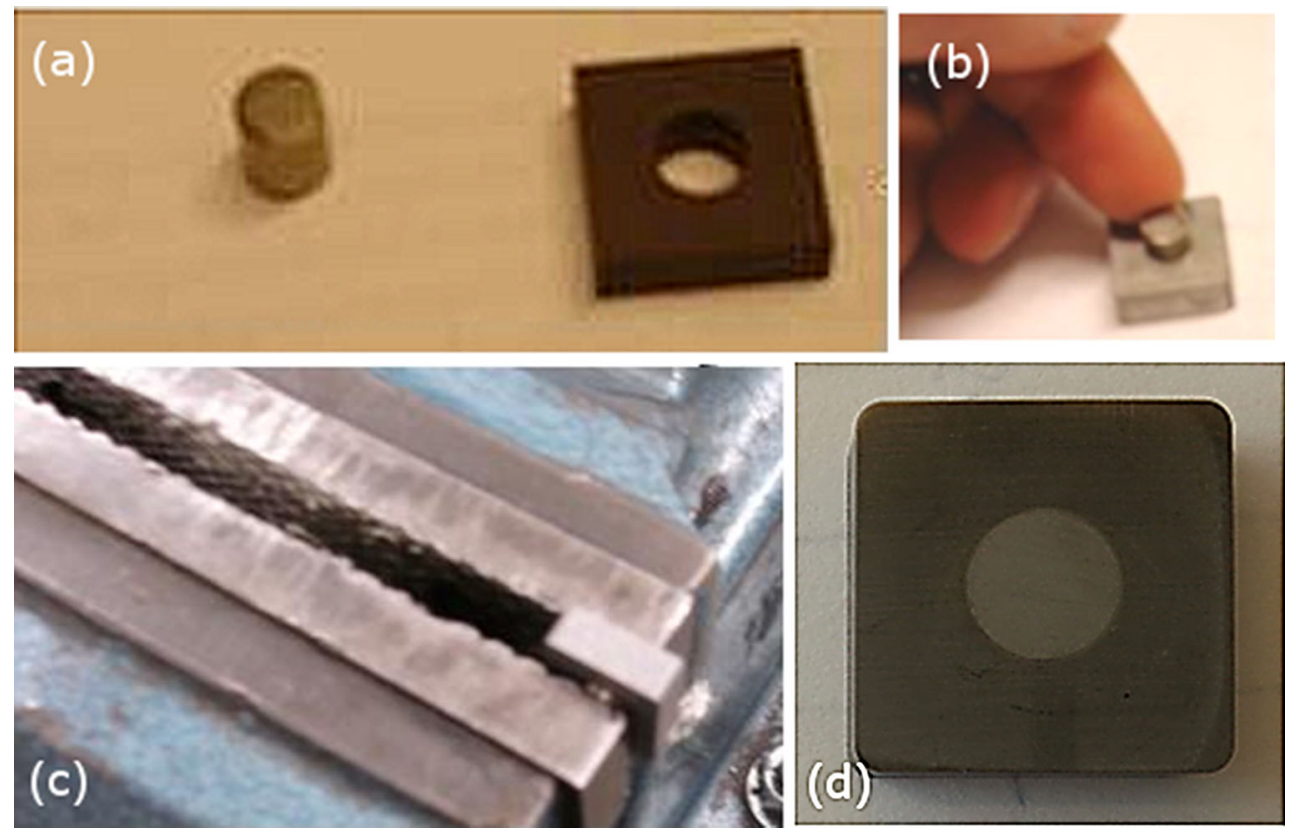

Fig. 1 A typical diffusion couple specimen where a rod of work material (a) is inserted into the hole of a cemented carbide insert with geometry ISO SNMA150612 (b) and pressed slightly (c) to achieve good contact between work material and tool (d) 
Electron back scattered diffraction (EBSD) data was obtained for the Ti-based sample using a Zeiss Sigma VP SEM equipped with an Oxford Nordlys EBSD detector.

\subsection{Thermodynamic and Diffusion Simulations}

Phase diagram calculations and diffusion simulations were performed using Thermo-Calc and DICTRA respectively ${ }^{[9]}$ in combination with the TCFE7 and MOBFE2 thermodynamic and kinetic databases. ${ }^{[10]}$ The TCFE7 database has been developed with steels in mind and will thus yield most reliable results for Fe-based materials. However, initial calculations showed that the known phase equilibria of Co-based cemented carbides, along with $\mathrm{Ti}$, $\mathrm{Ni}$ or Fe, could be reproduced satisfactorily. The set-up of the diffusion calculations was performed in the same manner as described by Odelros et al. ${ }^{[8]}$

The experimental setup used in this work results in a curved interface between the workpiece material and the cemented carbide. This in turn affects the flux of atoms across the interface, compared to a planar geometry, which would have to be accounted for in the simulation. However, the radius of the cylinder is in this case large enough to approximate the interface as planar, as seen in the cross sections presented in Fig. 2.

Table 1 Work materials investigated in this study

\begin{tabular}{l} 
Work material \\
\hline Commercially pure titanium: Ti (99.7\%) \\
Titanium alloy: Ti-6Al-4V \\
Pure Nickel: Ni (99.5\%) \\
Nickel-based alloy: Inconel 718 \\
Pure iron: Fe 99.95\% \\
Austenitic stainless steel: AISI 316L \\
\hline
\end{tabular}

\section{Results and Discussion}

\subsection{Ti and Ti-6Al-4V}

Interactions between pure $\mathrm{Ti}$ and the tool were found to be severe, as is seen in Fig. 2(a). A dark rim with separated bright regions was formed at the interface between the titanium rod and the cemented carbide (region $\mathrm{X}$ in Fig. 2a). Next to this, a region with enhanced $\mathrm{W}$ and $\mathrm{Ti}$ content was formed (region Y in Fig. 2a). The cross section was analyzed with EDS-analysis where it was found that the rim consisted of $\mathrm{Ti}$ and $\mathrm{C}$, and that the brighter islands consisted of tungsten (Fig. 3a). The interface was further analyzed with EBSD to identify the phase content of the regions in the interface. The EBSD analysis of region $\mathrm{X}$ (Fig. 3b) showed a NaCl-structure type $\mathrm{TiC}$ phase (green) and bcc $\mathrm{W}$ (yellow). In region $\mathrm{Y}$ a bcc phase containing Ti and $\mathrm{W}$ was detected. Normally, only $\eta$-phase would form upon loss of carbon from the cemented carbide. However, it has been shown previously, that bcc-W will form in a Ti/ cemented carbide diffusion couple, as well as during machining ${ }^{[8]}$ in agreement with the results presented here.

According to the diffusion simulations shown in Fig. 4, bcc-W will in fact form almost instantly, due to formation of $\mathrm{TiC}$, and will later dissolve gradually into the bcc-Ti matrix phase. At $1100{ }^{\circ} \mathrm{C}$, bcc-W is thermodynamically favored for $\mathrm{C}$ mole-fractions below 0.5 in the $\mathrm{W}$-C system (Fig. 5). At temperatures above $1250{ }^{\circ} \mathrm{C}$, the stable decarburized phase would be $\mathrm{W}_{2} \mathrm{C}$. Further studying the W-Ti phase diagram, there is a miscibility gap between 50 and 75 wt. $\%$ W at $1100{ }^{\circ} \mathrm{C} \cdot{ }^{[11]}$ At compositions $\mathrm{x}(\mathrm{Ti})>0.75$, bcc-W is miscible in bcc-Ti. This explains the existence of a cubic phase where $\mathrm{W}$ and $\mathrm{Ti}$ are intermixed in region $\mathrm{Y}$ in Fig. 2(a) and 3(b). None or very little Co was detected in the investigated region closest to the interface. Further analysis deeper into the Ti work material points at a long diffusion zone of Co into the work material. Similar results (slightly thinner diffusion zones) were obtained upon

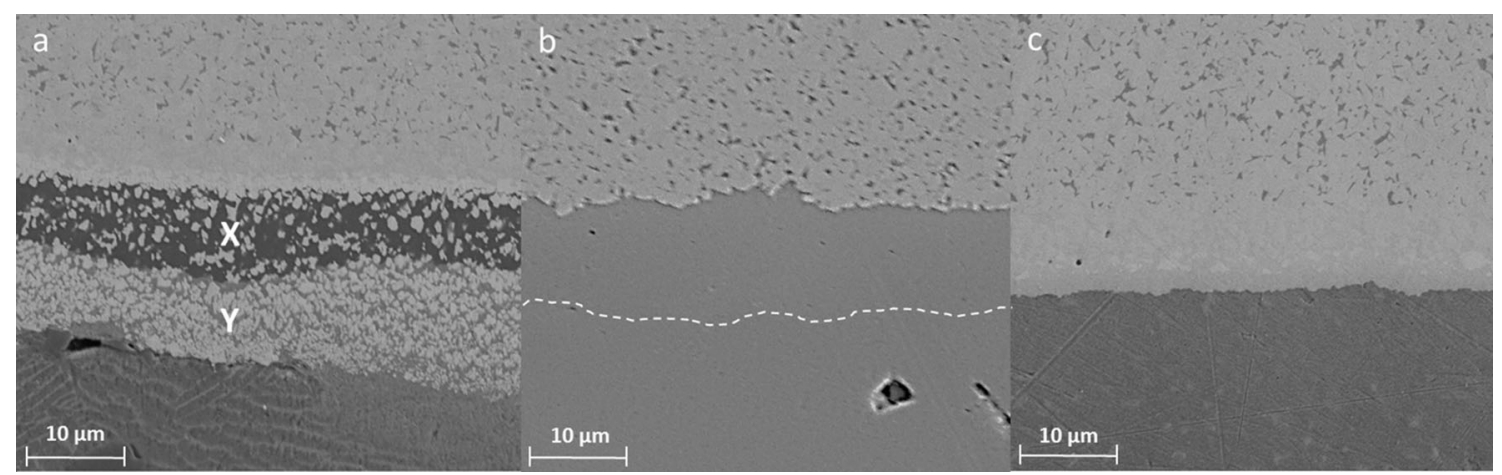

Fig. 2 SEM micrograph of (a) Ti- tool interface, (b) Nickel- cemented carbide interface (weak contrast difference marked by white dashed line, (c) Inconel718- tool interface 


\section{a}
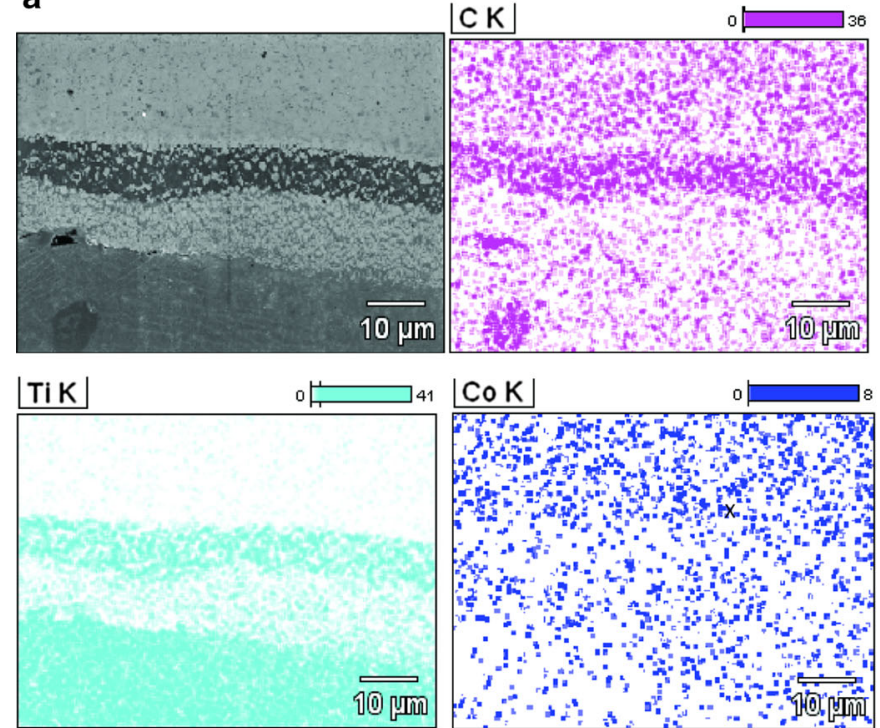

WM

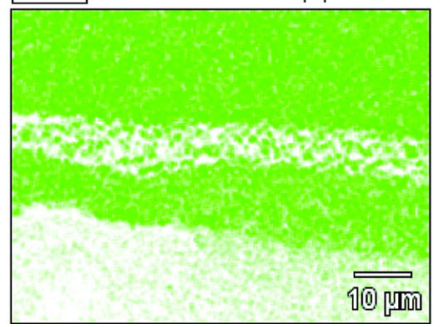

b

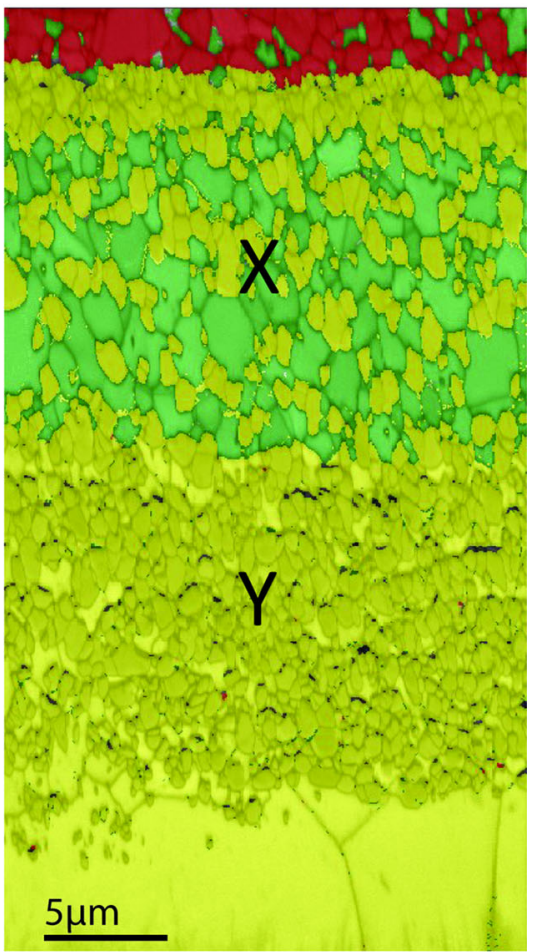

Fig. 3 (a) EDS map of cemented carbide-Ti interface (b) EBSD map of cemented carbide-Ti interface (COLOR). The titanium carbide phase is shown in green and the cubic tungsten phase in yellow (Color figure online)

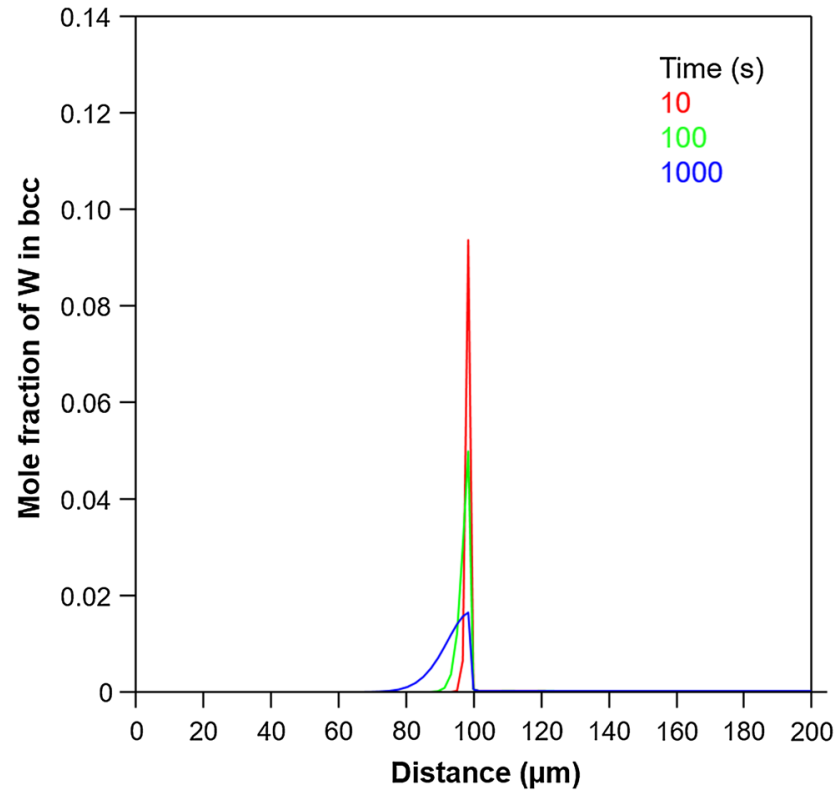

Fig. 4 Simulated $\mathrm{W}$ content in the bcc phase in the Ti/cemented carbide diffusion couple. Initial interface is centered at $100 \mu \mathrm{m}$. The widening of the peak with time indicates dissolution of the $\mathrm{W}$ into the bcc matrix of the Ti workpiece

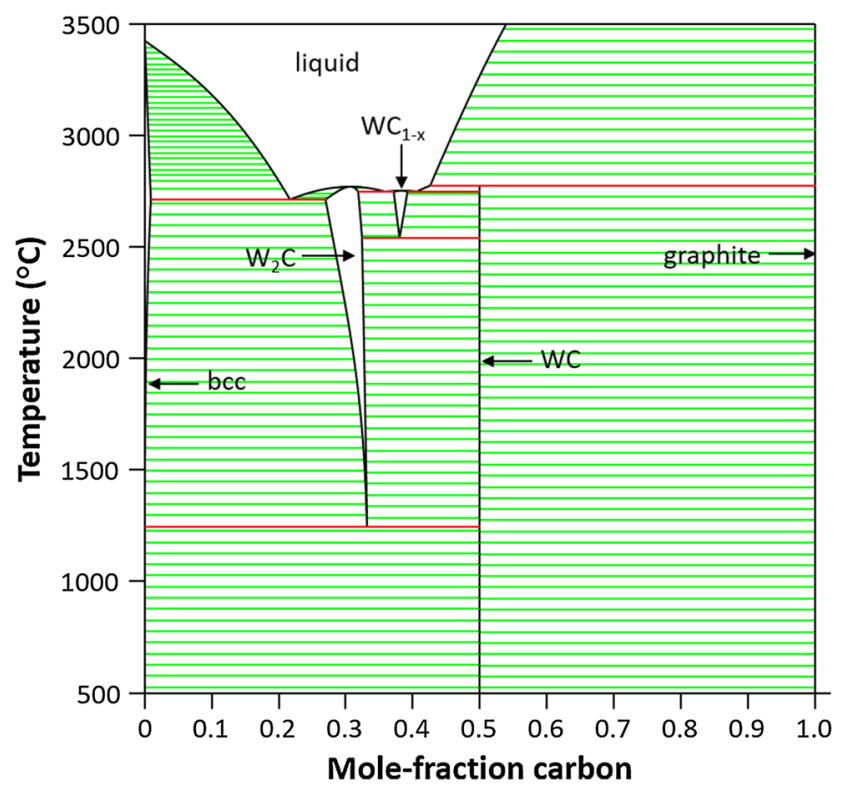

Fig. 5 W-C phase diagram 
changing the work material to Ti-6Al-4V. The results from the titanium couples indicate that carbon from the tool has diffused into the titanium rod and formed $\mathrm{TiC}$ at the tool/work material interface. Upon carbon depletion in the binder phase, WC grains start to dissolve and metallic W forms.

\section{2 $\mathrm{Ni}$ and Inconel718}

In Fig. 2(b) the tool-Ni interface appears homogeneous, however. the interface was further analyzed by WDS and compared with simulated diffusion profiles (Fig. 6), showing excellent agreement as to the trends for the different elements. It was concluded that a cobalt gradient into the Ni rod is formed. This is in good agreement with the Co-Ni phase diagram, where complete solubility of Co and $\mathrm{Ni}$ occurs in the fcc phase throughout the whole solubility range at $1100{ }^{\circ} \mathrm{C}^{[12]}$

To obtain absolute values from WDS measurements suitable reference materials with known composition and which closely resemble the sample are required. The situation becomes even more complex when materials with widely different compositions are studied in the same sample, as is the case in a diffusion couple. The limited accuracy of WDS-measurements of such a system is evident in Fig. 6, where the $\mathrm{Ni}$ content should approach $100 \mathrm{wt} . \%$ to the right of the interface and zero close to the left of the interface, as is seen in the simulated result. Similarly, the Co and W contents obtained

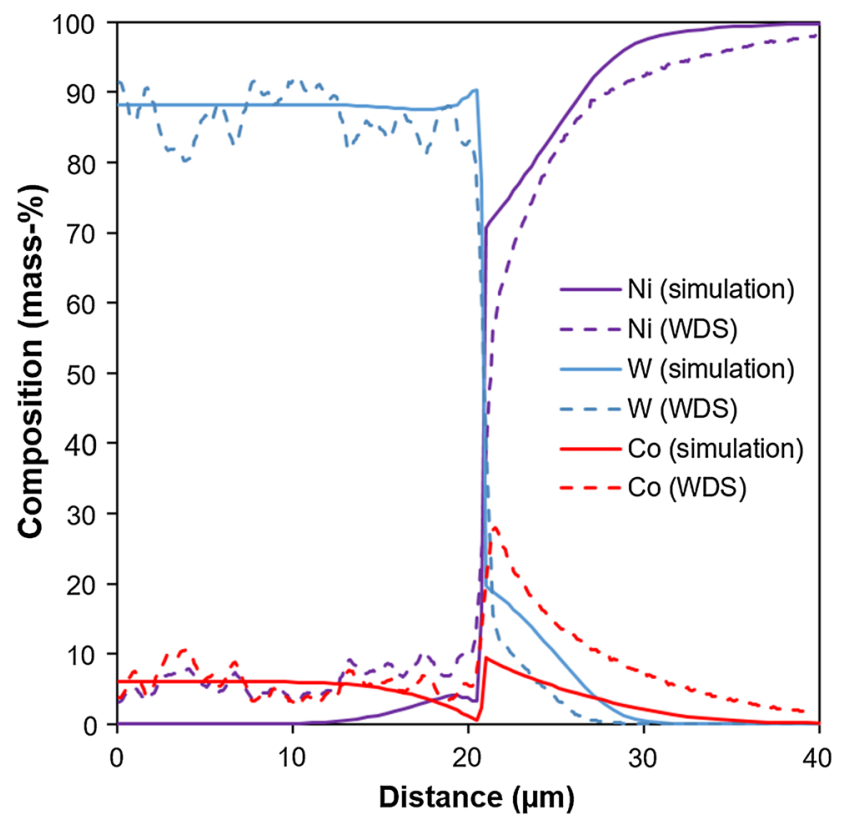

Fig. 6 Comparison of simulated and measured diffusion profiles for $\mathrm{Ni}, \mathrm{W}$ and $\mathrm{Co}$ in the $\mathrm{Ni} /$ cemented carbide diffusion couple from WDS in the Ni-rich side of the diffusion couple are higher and lower, respectively, as compared to the simulated result.

The occurrence of a diffusion profile, with exchange of $\mathrm{Co}$ and $\mathrm{Ni}$ between the matrix phases of the two sides of the diffusion couple, is consistent with the fact that Ni does not form any stable carbide on its own (contrary to Ti). Furthermore, as compared to $\mathrm{Co}$ or Fe containing binder phases, Ni will shift the $\eta$-phase limit to lower carbon contents and thus no stable $\eta$-phase will form (Fig. 7). For these reasons, there will be no carbide layer present at the interface to inhibit diffusion, in contrast to the case with $\mathrm{Fe}$ or Ti.

Further simulations were performed at a lower carbon content in the cemented carbide part of the diffusion couple, in order to investigate if $\eta$-phase could form at lower carbon contents (Fig. 8). The results show that $\mathrm{M}_{12} \mathrm{C}$-type $\eta$-phase appears initially as a transient phase, but dissolves completely after less than $30 \mathrm{~s}$. The total carbide phase fraction never reaches unity.

Interactions between cemented carbide and Inconel 718 proved to be of a different nature, as can be seen in Fig. 9(a) and (b). This couple was analyzed with LOM combined with Murakami's etchant, which revealed an etched zone at the interface between the tool and the work material (Fig. 9b). Since Murakami's etchant is designed to erode $\eta$-phase only, it was concluded that this zone indeed did consist of $\left(M_{6} C\right.$ or $\left.M_{12} C\right)$. The reason to why $\eta$-phase was formed in this region is most probably carbon depletion of the tool. This is consistent with the fact that Inconel 718 contains $>20$ wt. $\% \mathrm{Fe}$ and that $\mathrm{Fe}$ is known to shift the $\eta$-phase limit to higher carbon contents.

\subsection{Pure Fe/316L}

The interactions between pure Fe and cemented carbide were very similar to those between low carbon austenitic steel (316L) or Inconel 718 and cemented carbide. As can be seen in Fig. 9(c), a white rim has formed at the interface. Such a rim also formed in the $316 \mathrm{~L} / \mathrm{cemented}$ carbide couple (Fig. 9e) and at the interface of the Inconel 718/cemented carbide couple (Fig. 9a). These couples were etched with Murakami's etchant, Fig. 9(d) and (f), pointing towards the conclusion that the rim consisted of $\eta$-phase. The couples were analyzed with EDS (not shown here) and in both cases the analysis revealed that the rim consists of iron and tungsten (as well as chromium in the $316 \mathrm{~L}$ case).

Diffusion simulations of the Fe/cemented carbide diffusion couple confirmed the occurrence of $\eta$-phase, since $\mathrm{Fe}$ will shift the $\eta$-phase limit to higher carbon contents. The simulation in Fig. 10 showed that the total amount of $\eta$-phase and WC will quickly reach $100 \%$ at the interface, strongly inhibiting further diffusion across the interface. 

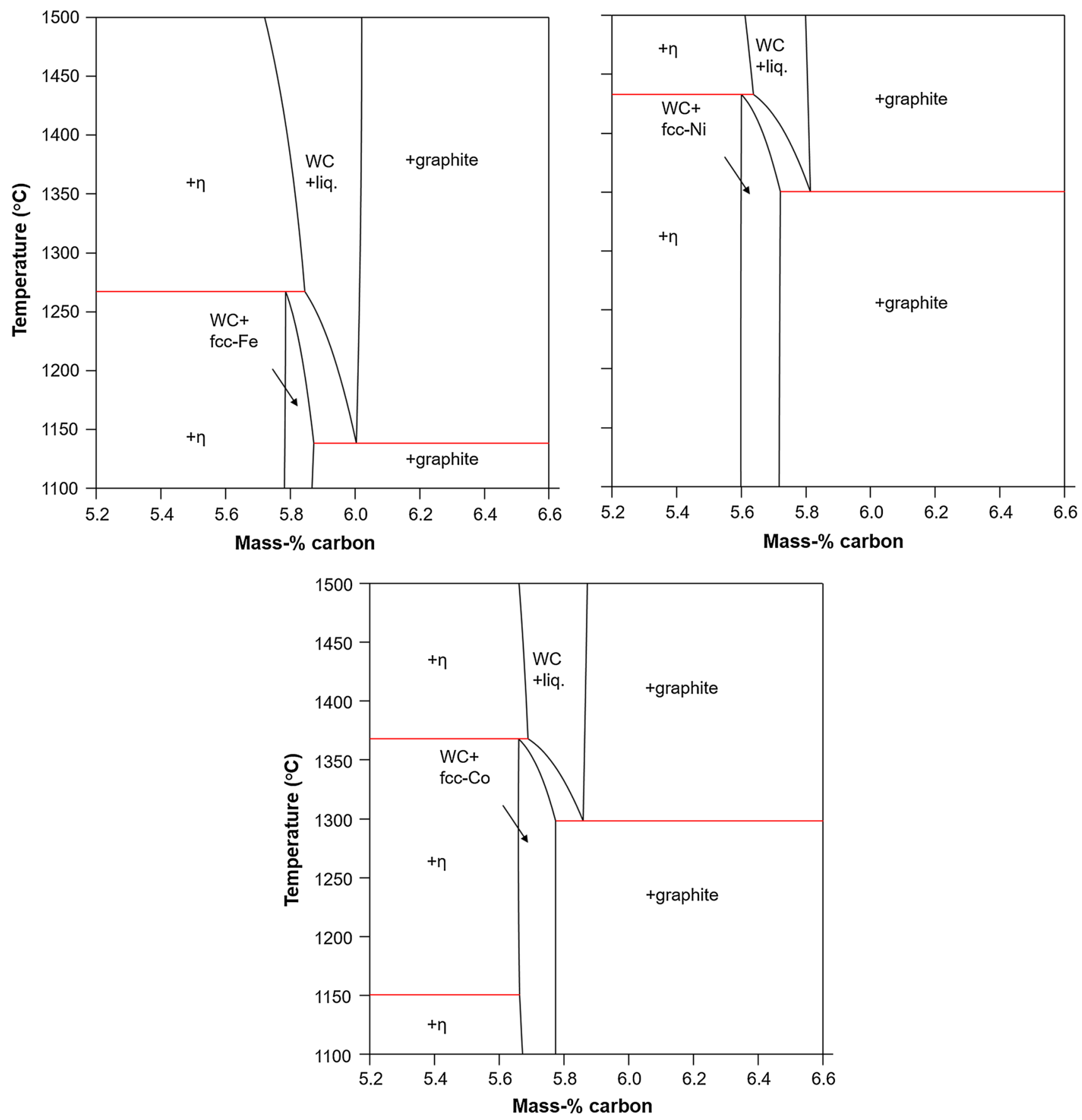

Fig. 7 Calculated isopleths of WC with 6 mass \% of Fe (upper left), $\mathrm{Co}$ (bottom center) and $\mathrm{Ni}$ (upper right). Note how the $\eta$-phase limit is shifted to lower carbon contents in the order Fe-Co-Ni. The very

This is in agreement with the diffusion couples, where a dense band of $\eta$-phase is present across the entire interface, intermixed with WC at the cemented carbide side of the diffusion couple, for all samples containing $\mathrm{Fe}$ (pure Fe, 316L and Inconel 718). Furthermore, the simulations of the diffusion couple with $\mathrm{Fe}$ indicated that formation of $\eta$ phase occurs irrespective of the carbon content in the cemented carbide. similar molar masses of $\mathrm{Fe}$, $\mathrm{Co}$ and $\mathrm{Ni}$ permit accurate comparison even when using mass percentages

\section{Conclusions}

Pure $\mathrm{Ti}$ and $\mathrm{Ti}-6 \mathrm{Al}-4 \mathrm{~V}$ interact strongly with the tool causing TiC-formation and dissolution of WC-grains. In agreement with previous studies, it is shown by diffusion simulations and EBSD analysis that bcc-W will form at the tool/Ti interface and progressively diffuse into bccTi. 
The tool-Ni interface does not contain any carbide phase, which can be explained as follows. Ni does not form any stable carbide on its own (contrary to Ti) and will in addition shift the $\eta$-phase limit to lower carbon contents, as compared to $\mathrm{Co}$ or Fe containing binder phases. Thus no stable $\eta$-phase will form. Diffusion of Co and $\mathrm{W}$ into the $\mathrm{Ni}$ work material was observed in both simulated and measured data.

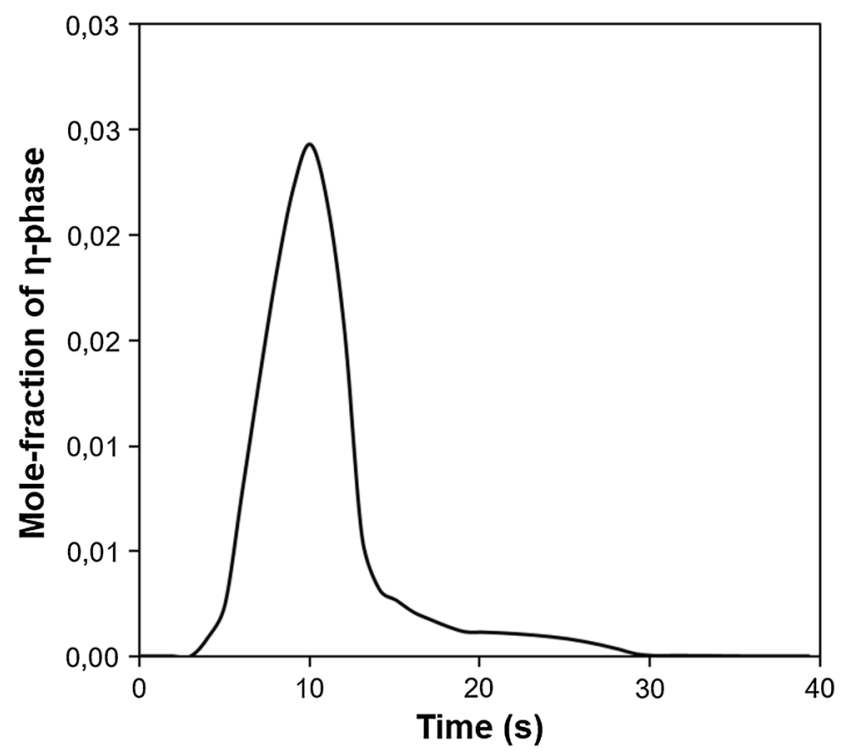

Fig. 8 Simulated mole fraction of $\mathrm{M}_{12} \mathrm{C} \eta$-phase at the interface, as a function of time for the $\mathrm{Ni} /$ cemented carbide diffusion couple
At the tool-Inconel 718 interface, $\eta$-phase was formed. The $\eta$-phase formation in this Ni-based alloy can be explained by that Inconel 718 contains $>20 \mathrm{wt} . \% \mathrm{Fe}$, where $\mathrm{Fe}$ is known to shift the $\eta$-phase limit to higher carbon contents.

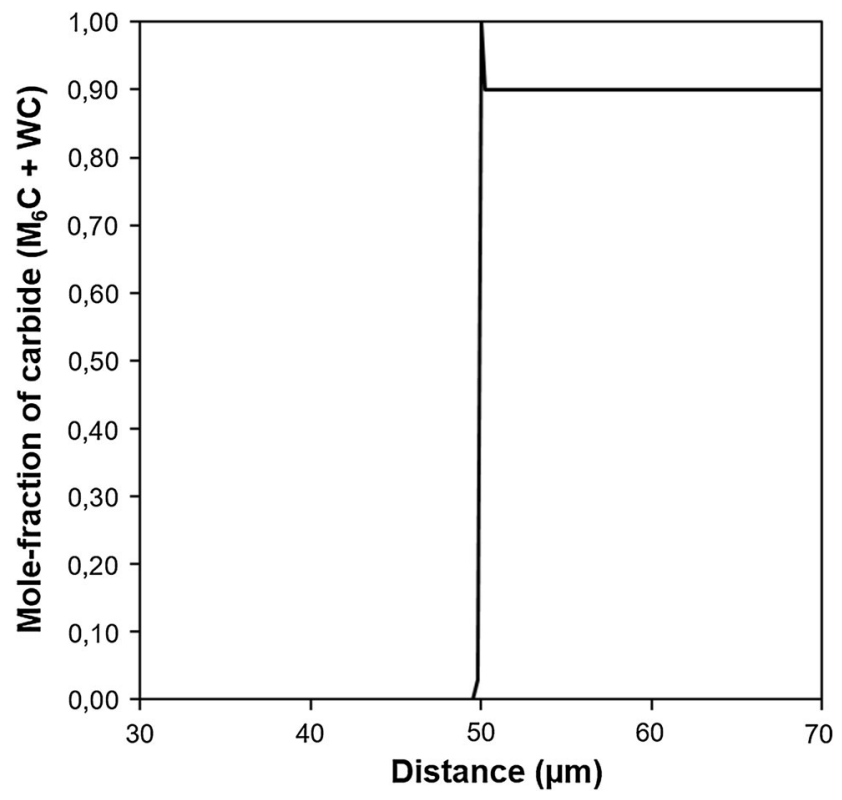

Fig. 10 Simulated mole fraction of $\eta$-phase $+W C$ after $10 \mathrm{~s}$ in the $\mathrm{Fe} / \mathrm{cemented}$ carbide diffusion couple. The original interface is centred at $50 \mu \mathrm{m}$. The total width of the simulated region is $100 \mu \mathrm{m}$
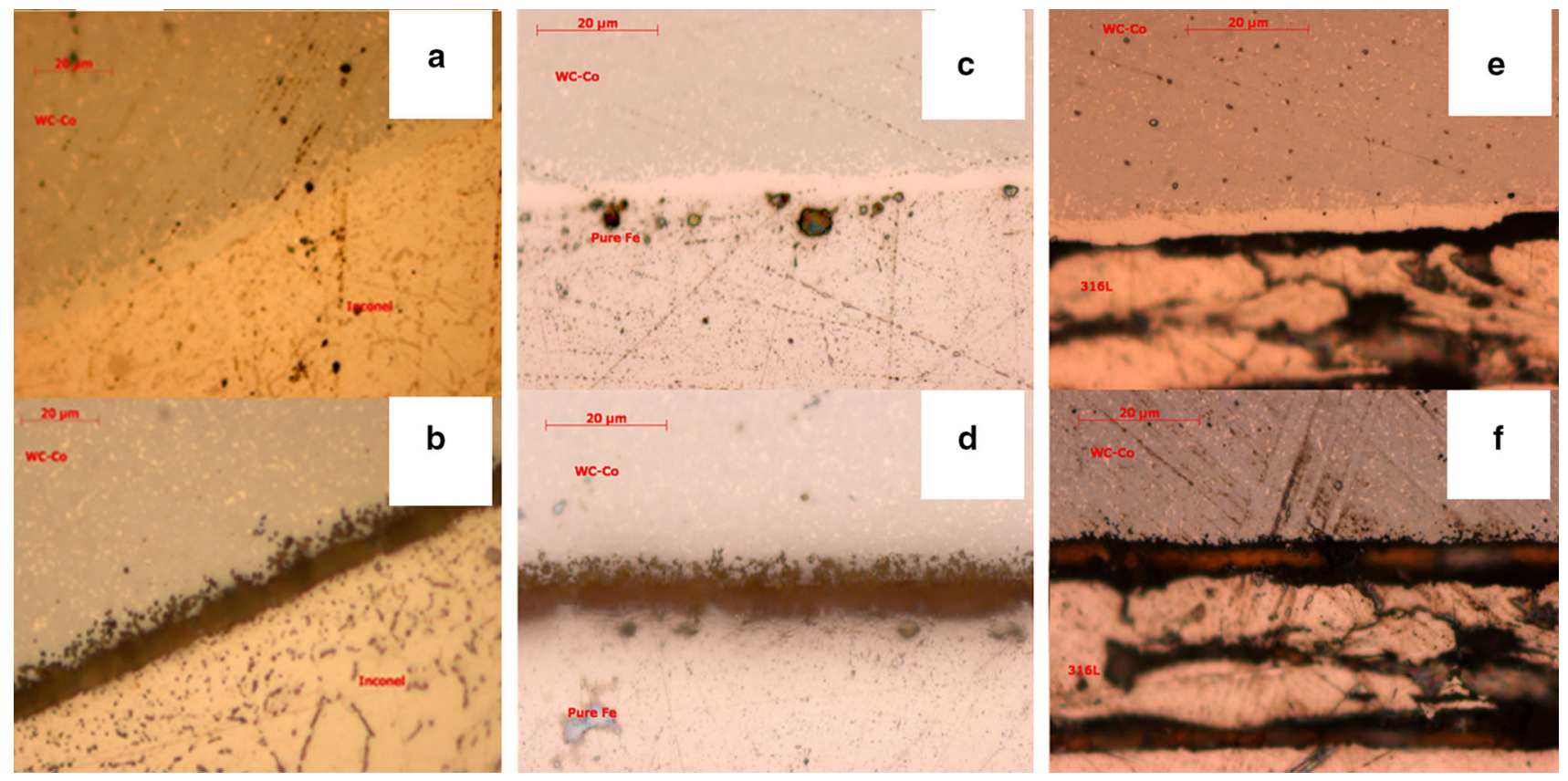

Fig. 9 LOM images of (a) Inconel718-tool interface (b) inconel718-tool interface (c) pure iron-tool interface, (d) pure iron-tool interface etched, (e) 316L-tool interface, (f) 316L-tool interface etched (COLOR) (Color figure online) 
As for Inconel 718, both low carbon austenitic steel and pure iron exhibit $\eta$-phase formation. This suggests that the chemical interactions are not caused by $\mathrm{Ni}$ in the Inconel but rather by the alloying elements.

Agreement between the diffusion simulations, measured composition and observed phases at the tool-work piece interfaces is very good. Therefore the diffusion couple method used in this work, corroborated by simulations may prove useful in the detailed analysis of worn tools where chemical wear is dominant.

Acknowledgments The authors would like to dedicate this paper to the memory of their late colleague Bo Jansson who suggested this simple but yet very efficient method for performing diffusion couple experiments. Christer Fahlgren at Sandvik Coromant is also acknowledged for performing the WDS-analysis.

Open Access This article is distributed under the terms of the Creative Commons Attribution 4.0 International License (http://crea tivecommons.org/licenses/by/4.0/), which permits unrestricted use, distribution, and reproduction in any medium, provided you give appropriate credit to the original author(s) and the source, provide a link to the Creative Commons license, and indicate if changes were made.

\section{References}

1. D. Jianxin, L. Yousheng, and S. Wenlong, Diffusion Wear in Dry Cutting of Ti-6Al-4V with WC/Co Carbide Tools, Wear, 2008, 265, p 1776-1783
2. A. Devillez, G. Le Coz, S. Dominiak, and D. Dudinski, Dry Machining of INCONEL 718. Workpiece Surface Integrity, $J$. Mater. Process. Technol., 2011, 211, p 1590-1598

3. S. Giménez, S.G. Huang, O. van der Biest, and J. Vleugels, Chemical Reactivity of PVD-Coated WC-Co Tools with Steel, Appl. Surf. Sci., 2007, 253, p 3547-3556

4. S. Giménez, O. van der Biest, and J. Vleugels, The Role of Chemical Wear in Machining Iron Based Materials by PCD and PCBN Super-Hard Tool Materials, Diam. Relat. Mater., 2007, 16, p 435-445

5. M. Sokovic, Study of Diffusion Across PVD-Coated Cermet Tool/Workpiece Interface, Int. J. Microstruct. Mater. Prop., 2005, 1, p 24-37

6. M. Kalin, J. Vižintin, J. Vleugels, and O. van der Biest, Chemical Reactivity of Silicon Nitride with Steel and Oxidized Steel Between 500 and $1200{ }^{\circ}$ C, Mater. Sci. Eng. A, 2000, 281, p 2836

7. O. Hatt, H. Larsson, F. Giuliani, P. Crawforth, B.P. Wynne, and M. Jackson, Predicting Chemical Wear in Machining Titanium Alloys via a Novel Low Cost Diffusion Couple Method, Procedia CIRP, 2016, 45, p 219

8. S. Odelros, B. Kaplan, M. Kritikos, M. Johansson, and S. Norgren, Experimental and Theoretical Study of the Microscopic Crater Wear Mechanism in Titanium Machining, Wear, 2017, 376-377, p 115-124

9. O. Andersson, T. Helander, L. Höglund, P. Shi, and B. Sundman, Thermo-Calc \& DICTRA, Computational Tools for Materials Science, Calphad, 2002, 26(2), p 273-312

10. Thermo-Calc Software AB. http://www.thermocalc.com/

11. H. Baker and H. Okamoto, Alloy Phase Diagrams, Binary Alloy Phase Diagrams 2, 3rd ed., ASM International, Materials Park, 1991, p 379

12. U. Haschimoto, Relation Between the Allotropic Transformation of Cobalt and Some Additional Elements, J. Jpn. Inst. Met., 1937, 1, p 177-190 